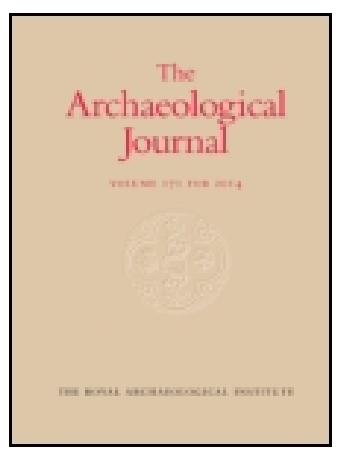

Archaeological Journal

\title{
On the Removal and Relaying of Roman Tesselated Floors
}

\section{Professor Buckman F.L.S., F.G.S.}

To cite this article: Professor Buckman F.L.S., F.G.S. (1856) On the Removal and Relaying of Roman Tesselated Floors, Archaeological Journal, 13:1, 215-227, DOI: 10.1080/00665983.1856.10851008

To link to this article: http://dx.doi.org/10.1080/00665983.1856.10851008

央 Published online: 10 Jul 2014.

Submit your article to this journal $[\pi$

Q View related articles $\longleftarrow$ 


\section{ON THE REMOVAL AND RELAYING OF ROMAN TESSELATED FLOORS,}

\section{BY PROFESSOR BUCKMAN, F.L.S., F.G.S.}

THE remarkable mosaic pavements discovered at Cirencester, in 1849 , were so striking in appearance as to lead all who saw them in situ to wish for their preservation. As they occurred, however, in the very midst of the most important thoroughfare of the town, it was evident this could not be effected without removal, a process attended with considerable expense, and requiring no little skill and address to take such a mass from its position, so that it might be removed to a more convenient spot, and be ultimately relaid in as perfect a state as at the time when the discovery had taken place. This too had to be achieved in a short time, as the road was inconveniently obstructed by delaying the sewerage works then in progress. In this emergency some gentlemen of the town, foremost among whom was the Rev. Canon Powell, applied to the Earl Bathurst for his counsel and assistance. The noble earl, with his usual generosity, directed that the pavements should be forthwith removed, with a view to their future preservation.

In the meantime, tracings of the floors, as they were gradually explored, were made by Mr. Cox, of Cirencester, assisted by the vicar and some of the professors of the Royal Agricultural College, and even a few of the students shared in the work. A busy scene it was, to see all these volunteers kneeling and patiently tracing, stone by stone, the complicated details, of which the colours in the fresh state were carefully matched by Mr. Cox.

This done, the two fine floors were removed piecemeal, and carefully conveyed to a temporary resting-place with the view of forming ultimately, as they do at this moment, the permanent pavements of a suitable building erected for them by the liberality of the Earl Bathurst, destined to form a Museum of the Roman Antiquities of Corinium.

The removal, and an equally important undertaking, the 
relaying, of these parements has been a matter of no small anxiety to those concerned, and as the result shows, has been satisfactorily accomplished, notwithstanding the little information that could be derived from precedents or written descriptions of the processes previously employed. It lias been thought advisable that I should bring the subject under the attention of the Institute, detailing step by step the expedients to which we had recourse in accomplishing our object at Cirencester. In connection with these observations it may be advisable to direct attention to the following: subjects :-

1st. The construction of different kinds of Roman tesselated parements.

2nd. The operations connected with their removal dependant thereupon.

3rd. Relaying and reparations of removed floors.

Roman pavements are usually of two descriptions. A finer kind, consisting of various borders and frets employed as a frame-work to pictorial subjects, and usually supported on pilce. A coarser kind composed of frets without pictures, and resting on a solid base, without pila.

The first of these are designated as suspensur $a$, being elevated on a number of small supports or pillars, called

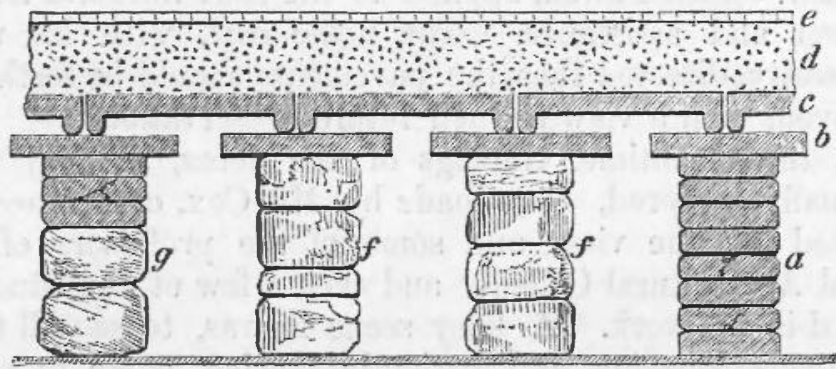

Tesselated pavement, laid on flanged tiles. a. Pilke of bricks; $b$. larger bricks; $c$. flanged tiles; $d$, conerete; $e$. tessellæ; $f$. Piles of squared blooks of stone; $g$. Pulce, part stone aud part bricks.

pile, composed of different materials, amongst which are hollow bricks, or flue-tiles; solid flat bricks or wall-tiles; blocks of stone, and bases of old columns. Upon these supports a continuous floor was formed, either of large flat tiles of considerable thickness, or of thinner flanged tiles, which are sometimes placed with the flanges upwards, sometimes in the other direction. Upon a floor so prepared was laid 


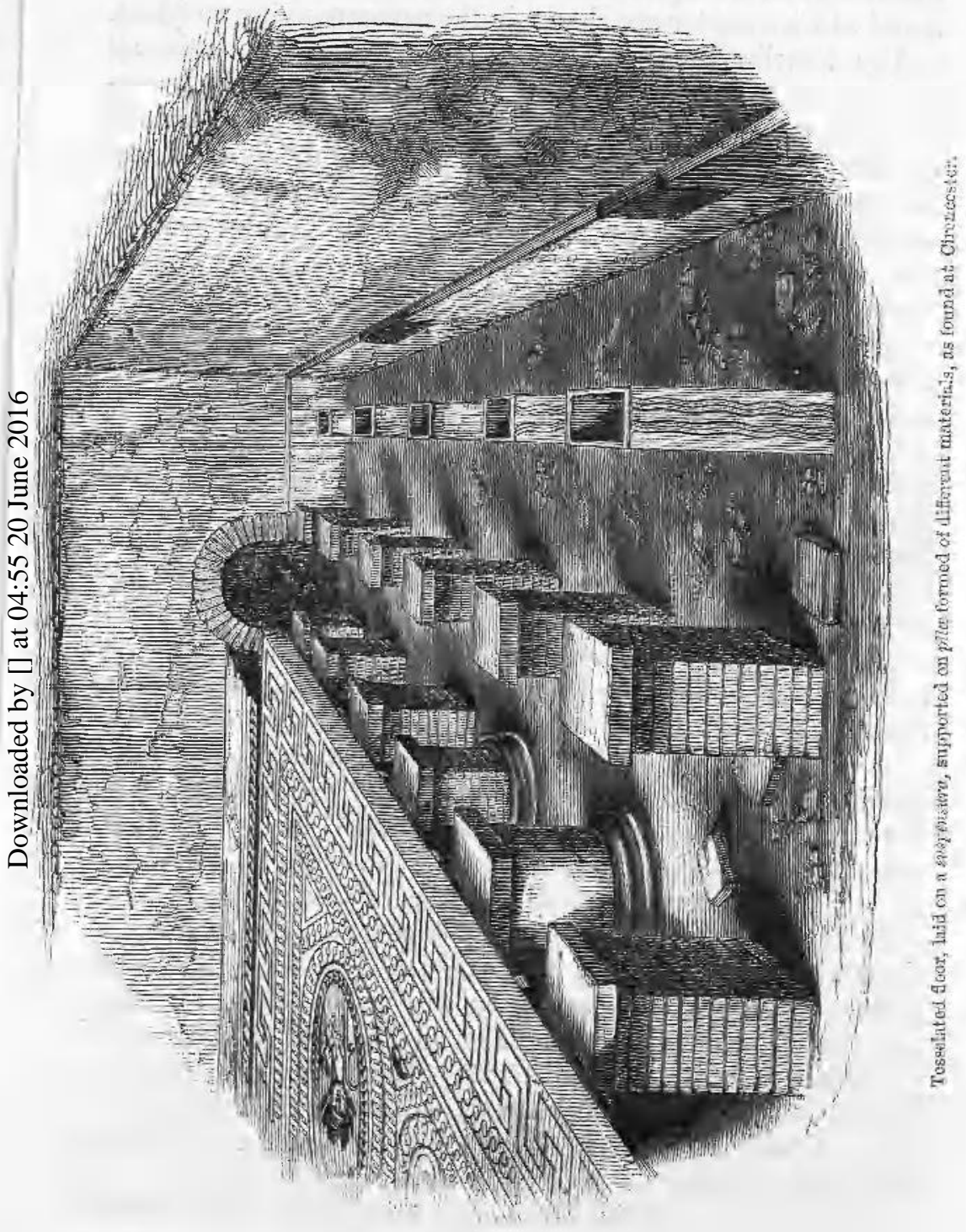


a thick mass of a very hard concrete, composed of potsherds, gravel, and lime which was made into a smooth terras for the reception of the tessellæ. ${ }^{1}$ The various kinds of pila found at Cirencester are shown in the accompanying woodcut.

The tessellæ themselves deserve careful attention in all processes connected with their removal, as it will be necessary to restore certain parts that must be displaced in dividing the floor into portions for convenience of transport. All the fragments so taken out, as indeed all loose tessella, should be carefully preserved for further use. But besides this, the examples of stone and other materials in our pavements were cautiously investigated by the geologist and the chemist, and their determinations of the kind and nature of the substances employed were found of great use in the restorations subsequently undertaken.

The list of these substances included, besides pottery and glass, stones from the following geological formations:-Chalk; Purbeck Marble ; Oolitic stones of various shades of colour; Lias Limestone; New Red Sandstone, and Old Red Sandstone. Some of these, especially the oolites, had evidently been made suitable for different degrees of coloration by some curious processes. These and the preparation of the ruby glass have been more fully set forth in the "Illustrations of Ancient Corinium," by Mr. Newmarch and myself.

As respects the subjects usually pictured, they have reference mostly to mythology and objects connected with the chase. The story of Orpheus is one of those of frequent occurrence; no less than four times has this subject been repeated in different parts of Gloucestershire.

If I might venture a remark upon the construction of these pictures as an art, one would almost be led to think that designs were first made by tolerable artists, and that these in all probability were gradually worked by persons of inferior skill, or even members of the household. There is an unevenness in the working, apparently from having been done at different times, and by various hands. Some of the pavements at Cirencester, moreover, are found in an unfinished state, whilst others, and especially those which we have removed, are patched in several places in a way

1 The method of constructing tesselated floors will be found more fully explained in the "Illustrations of the remains of
Roman Art, in Cirencester," by Prof. Buckman aud Mr. Newmarcli, 1850. 
that marks reparation at various periods. It may therefore be possible, that these elaborate floors were the result of that kind of patience more recently expended on "Berlin work" and embroidery, a notion which seems in some measure confirmed by the delicate working of sprigs of flowers, endless knots, and intricate guilloches, which characterises the decorations of this class.

The common tesselated floors were formed by smoothing the earth, and upon this was then laid the concrete prepared as above described. Upon this, beautiful geometrical and other patterns were often laid, but seldom any designs comprising figures or subjects of the higher class of art.

Occasionally in excavations at Cirencester I have met with pavements constructed as just described, one over the other, in such a manner as to lead to the inference that the higher floor was formed to escape an inundation, which seems to have visited the valley once in about half a century. In 1833, there was a flood of this kind, when all the cellars in the town were filled with water, and I observed that while the upper of these double floors were beyond the limits of the flood, the lower floor would have been inundated.

2nd. The two kinds of construction, to which I have briefly adverted, of course necessitated very different methods to be adopted in removal of the pavements. As regards pavements on pilce, the following was the course pursued :--The first process was to cause the floor to be divided into smaller portions. This was done by removing the rows of white tessellæ from around the circles, semicircles, and quadrants of our two large pavements, and then with chisels and stone-saws cutting through the concrete to the very base of the terras. By these means the pavements were divided into portions of various weights and sizes, which had to be finally prepared for removal.

It is obvious that the edges of these large heavy blocks would be liable to break away, and some of the concrete would unavoidably crumble, in the jolting necessitated by the carriage from one place to another. To prevent the former, a thin coating of plaster of Paris was run over the outer surfaces of the designs, upon which were laid pieces of blue slate. This process, however, in several instances was omitted, but in its stead a hoop of iron was fastened around the edges, a plan which succeeded much better, as the 
plaster, on its removal, tore away many of the looser tesseræ of the design.

The next step was to pass under the block to be removed slabs of wood, consisting of two or more, according to the size of the portion of pavement. Into these were screwed long iron loop-screws, through the loops of which poles could be passed, and the whole might be lifted either by men or by pulleys, and placed on a truck to be conveyed away. The same mechanical means were resorted to to deposit the mass in the place of temporary rest, and then the screws were taken out to be employed in the same way for the other portions.

This apparatus of the boards and screws is very simple, as it was only necessary to readjust the screws in order to remove the blocks at any time to their final resting-

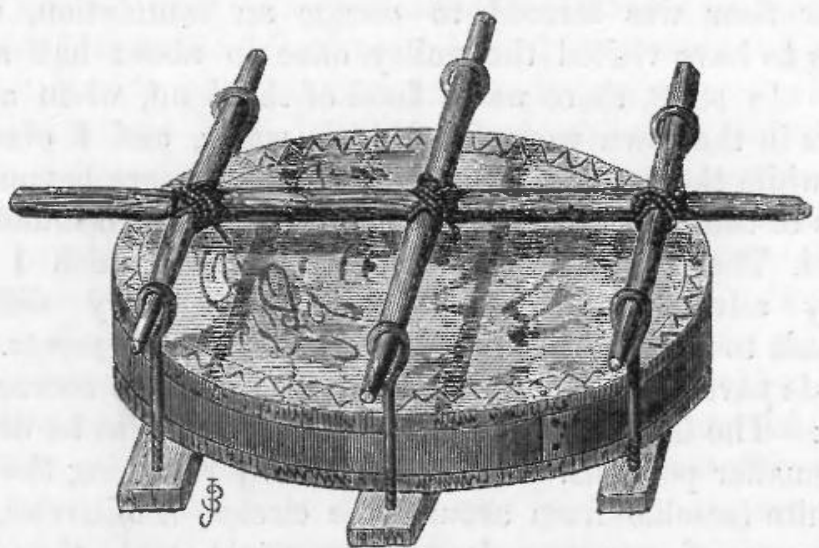

Portion of a tesselated floor, packed for removal. Weight, about $12 \mathrm{cwt}$.

place, and one set of screws sufficed for the whole. It should be borne in mind that some of the blocks were of great weight, and consequently much strength of apparatus had to be employed. The annexed diagram shows one of the blocks prepared as described.

Here then, in the case of a suspensura, it was tolerably easy to get to all sides so as to adjust the apparatus, as described; but where the pavement was laid on a solid ground terras the difficulties were increased, as not only had the soil to be gradually removed from below, so as to admit the packing for its support and removal, but parements so constructed are usually not so well preserved as those placed 
on suspensus a ; these mosaic floors have suffered more from damp, and consequently the tesseræ are often much broken and displaced. If then such a pavement can be removed in divided blocks, like those before described, upon carefully working underneath them, that mode of proceeding is preferable, and we have then solid slabs for relaying; but if too broken or too fragile for this process, it is well to look only to the tesseræ, and adopt a plan to remove it in pieces from the concrete substratum, which can be done in this as in all cases of loose tessella, by spreading a cement made of a mixture of resin and bees' wax on rough pieces of canvas, and applying it hot, carefully adjusting it to the floor to be removed. This enables the operator to remove all the tesseræ in such a state as to be capable of being put away on any flat surface for future replacement. This plan is well adapted for all small portions of pavement, which it may be desired to preserve, as it can be readily adopted where every other expedient would be unsuccessful.

It may be well here to give the result of our experience as regards the temporary deposit of pieces of pavement so removed. Many of the slabs prepared as described were removed to one of the lateral chapels of the parish church, others to Earl Bathurst's coach-house, but the greater part were laid upon a lawn, and a temporary canvas building erected over them to protect them from the weather. Of these, the portions placed in the church were badly preserved; "those in the coach-house proved to be in better condition, whilst the portions protected by the tent were in the best state; and, as they had to remain in these positions some time, while a building was in course of erection for their final reception, it is a matter of congratulation that the injury anticipated from atmospheric causes did not arise. The truth being that too dry a state of the air, whether from their sudden removal from the bed in which they have lain for so many centuries, or from whatever other cause, is injurious, as tending to crack and separate the tessellæ one from another, as also to split off masses of the concrete; and as the plaster of Paris had been applied to those in the church, in the manner previously described, its subsequent removal occasionally caused the breaking off of large portions of the design. That in the tent was never too dry, and consequently its liability to crack was not so great; and it may be mentioned with 
respect to these pavements now they are relaid, that constant washing may be considered beneficial rather than prejudicial to their preservation.

3rd. On relaying and repairing Roman floors.-In the case before us, we have to congratulate ourselves upon the erection, through the Earl Bathurst's liberality, of a most suitable and substantial building for the reception of the two floors discovered in Dyer Street, in 1849.

In buildings for this purpose two circumstances ought to be provided for, a thorough rentilation, and a perfectly dry atmosphere. The first is secured by windows that can be readily opened. The second, we hope, has been accomplished, by making a deep drain around the outside of the building, to keep the walls dry at their foundations. The ground on which the pavement is laid was, at the recommendation of Mr. Digby Wyatt, prepared by a layer of concrete 2 feet thick, which has the effect, besides keeping the base dry, of forming a strong and immovable foundation for the reception of the pavement.

I would here express the thanks of all those interested in the preservation of these pavements, for the valuable suggestions kindly sent by Mr. Wyatt; at this time our pavements had been removed, but his instructions were of great use in facilitating the relaying of them, and were implicitly followed. To his valuable advice on this occasion, given in the most friendly manner at the request of Mr. Albert Way, we owe much of the success with which this difficult undertaking has been achiered. ${ }^{2}$

The building having been completed, the noble earl, on whose property it is placed, put the whole matter of relaying the pavements into the hands of the Rev. Canon Powell and myself, giving us in the most liberal manner every facility as to workmen, and all the requisite arrangements. At this stage of the proceeding, we deemed it advisable to apply to Mr. Minton, to recommend us a person expert in laying floors, and he sent us in Mr. Allen, a coadjutor in every way

\footnotetext{
2 I must take this occasion to express my acknowledgment, and to offer the thanks of my Cirencester friends, to $M_{r}$. Tucker, and Mr. Albert Way, and other members of the Institute who have taken a cordial interest in the discoveries at Cirencester. Their sympathy and ready
}

aid on all occasions have had no slight influence in keeping alive amongst us a feeling which I hope may tend more and more to the preservation of the vestiges which illustrate the ancient condition and history of Corinium. 
suited to direct so difficult an operation. He entered upon the work in the spirit of one who was proud of being engaged on such an undertaking, and who had the taste and knowledge to appreciate the value of so remarkable a work of ancient art. Mr. Allen's first proceeding was to examine with great care the tracings of the floors, and when we had decided upon the positions they were to occupy in the room the work of relaying commenced in earnest.

The loop-screws previously described were screwed into the boards supporting the first portion to be removed. It was lifted on a spring-truck, so as to avoid injury from jolting, and from this it was moved to its future position, which having been accurately determined, the careful adjustment of the tesselated mass took place, by packing below with stones and bricks, and when perfectly levelled in its position a paste of Roman cement, made thin enough to run into every crevice, was carefully poured beneath the whole. By these means it was soon firmly established in its destined resting-place.

The other portions of the pavement followed one after another, and each upon being carefully adjusted to its fellow, was secured by the Roman cement, until the whole became joined together in a compact mass, which, from the manner of working, I conceive to be as smooth and secure as when the floor was originally formed. I would remark upon the adjustment of large pieces of work like that under consideration, ranging from half a cwt. to as much as a ton in weight, being all parts of a continuous pattern, that much patience and skill is required in fixing the first piece, and adapting the various portions one to the other afterwards. This was in our case rendered much easier by a careful study and admeasurement of our accurate tracings, which, to this end, were laid down in Earl Bathurst's hall, for constant study and reference during the progress of the work.

The various parts of the two pavements having been secured in position, in the manner described, then followed the gradual restoration of those portions which had been removed in dividing the floor into smaller masses. To this end, the variously-coloured tesseræ were assorted and washed. These were then restored for the completion of the designs, and adjusted in their places by a strong cement sent for the purpose by Mr. Minton, the whole being pressed 
evenly into their places by a flat block of wood. This, from the nature of the material, allowed considerable weight and pressure by blows or other means to be applied, without communicating a jar to the adjacent work. In some instances, great portions of a complicated guilloche or other border had to be replaced; in this case the pattern was arranged on a piece of board in the proper tessellæ, from which it was worked, bit by bit, into its appropriate place. In a few instances, owing to change from accident and other causes, the colours could not be matched, even by using the same geological materials as were originally employed, so that we had to seek the best substitutes for our purpose. In this case, a few of the coloured tessellæ manufactured by Minton were substituted'for the fictile, and even some of the stone, tessellæ of the ancient designs. I cannot, however, recommend the use of these, as they proved objectionable from their being formed in a mould and of uniform size. This regularity in dimensions, though it might at first appear to advantage, nevertheless takes from that freedom of design and effect which the ancient pavements present, from the very fact that stones of all shapes and sizes were. used to work out the intention of the operator.

In our restorations it should be understood that we have confined ourselves to the replacing what was unavoidably removed, in order to separate the floors into convenient pieces for carriage. An important question has been suggested upon which we are desirous of obtaining the opinion of archaeologists. Is it advisable in such operations to restore the broken designs? I confess, as the work progressed, I almost felt a wish to do this, but upon mature reflection, I was convinced that we could not carry out such a renovation without great disadvantage. It is true, we might have shown what the floor would have been if perfect, but it is a question whether the new work would not have essentially detracted from the archaic intent and authenticity of the pavement, and I cannot help thinking that such an example of the arts of antiquity, even in a fragmentary state, possesses a far higher interest and value as an instructive memorial of the past than the most skilful restoration.

As regards the relaying of floors of the second class, formed without suspensura, this of course must be done in the same manner, but the operation will require even more careful 
packing with the cement. If the tesseræ have been removed on the canvas by the adhesive process above mentioned, this must be pressed smoothly on a bed of prepared cement, and when set hard, the canvas and resin can be removed by gentle heat.

It now only remains to point out a difficulty which we experienced in keeping the surfaces of these floors sufficiently bright and clean. The tesseræ seem to be affected by two causes, chemical change, and the growth of mosses and minute fungi upon the surface, by which the designs are very much dimmed. In order to prevent this, I have experimented in several ways; one metbod proposed is by scrubbing with silver sand; this polishes the surfaces, but it is a work of great time and labour; another is the use of a Bath brick; this certainly cleans the tesselated floor very well, but I fear the constant cleaning which any plan would entail, may tend to loosen the tessellæ, and we have not the ready means at hand to repair such casual injuries, as was the case with the original occupants of the buildings in which these elaborate decorations were displayed, and to which these very examples bear witness. Would it therefore be desirable, when once cleaned, to rub them well with oil, or by some other means to protect the surface from future decomposition, arising from any such cause as has been mentioned above?

Having now detailed the processes employed in the removal and replacing of the Cirencester pavements, I can only hope that these remarks may draw forth some further observations upon this subject, or produce the result greatly to be desired - the publication of plain directions for proceeding with the preservation of such examples of ancient art, when they may be brought to light. In our case, much time and trouble might have been saved, had we been in possession beforehand of the practical knowledge which we have gained by experience. Scarcely a year elapses without the announcement of some fresh discoveries of these interesting vestiges of Roman occupation in our country ; from the peculiar nature of tesselated pavements, or the circumstances under which such discoveries mostly occur, it must frequently happen that valuable examples are destroyed or very imperfectly preserved, for the want of that very promptitude of action which the knowledge of the means most readily available would so essentially tend to ensure.

VOL. XIII. 


\section{SUPPLEMENTARY NOTES ON THE REMOVAL OF MOSAIC PAVEMENTS.}

The following counsels, from one so accomplished in every subject connected with archaeology and art as Mr. Digby Wyatt, cannot fail to prove acceptable. Professor Buckman has already adverted to the kindness with which Mr. Wyatt aided the undertaking at Corinium by his valuable advice :-

" It is difficult (Mr. Wyatt observed) to advise about the removal of a mosaic pavement without seeing its condition, and more especially the condition of the cement upon which it has been bedded. Under average circumstances I should be inclined to adopt the following course. After removing all dust, -

“1. With strong bookbinders' paste cover the whole surface of the pavement with brown paper in large sheets, as a security against the displacement of the tesseræ in the subsequent operations.

" 2. Make a hole in the earth at the margin of the pavement at a point where a line of cutting may best be made without interfering with the best parts of the work, such as figures, \&c., and then with a stonecutter's handsaw, or some such tool, cut through the pavement in one direction. Then,

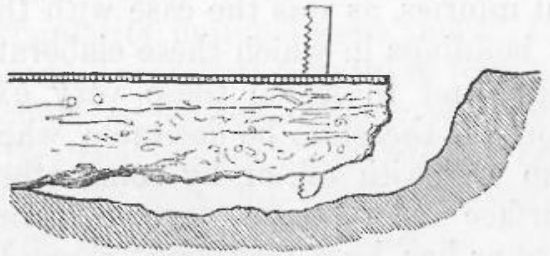
starting from another hole in the ground, make a cutting in an opposite line, so as to free a slab of about four feet square, -as much as can be conveniently managed. Some consideration and care must be exercised in dividing the pavement, so as to preserve the more important portions of the design uninjured; and it is obviously advisable to follow the leading divisions of the design, the borders, panels, \&c. The joint lines of the tesseræ may readily be found, after the pavement has been covered with paper, by rubbing down the paper, in the various directions in which the cuts have to be made.

" 3 . Each slab, as it is freed, should be carefully raised, and removed to a level floor, on which it should be laid face downwards. If the face of the tesselated slab is pretty true, and the old cement-backing in a good state, it will be enough for a mason to trim off the back to a rough face, so as to bring the slab to an uniform thickness of about four inches. If, on the contrary, the backing is friable and rotten, and has allowed the pavement to sink and lose its level, it will be necessary to remove it by flaking it away with a chisel, until the backs of the tesseræ are reached. When they are laid bare, a fresh backing must be made with Portland cement, pure, next the tesseræ (like a coat of whitewash) with sand, for about an inch in thickness, and then with gravel or fine concrete (lime and gravel) to the same thickness as the other slabs. I need not say that, when the tesseræ have had their old cement taken away, they should be pressed down to a level face before the new backing is put on.

" 4. When the slabs are all prepared, and are thoroughly set hard, they should be laid as ordinary paving slabs are laid in the best work, that is, on a good hard concrete bed. 
“ 5 . The brown paper may then be removed from the face of the pavement with hot water and a scrubbing brush.

“ 6 . The action of the scrubbing brush should be continued after the brown paper and paste are wholly removed, so that the joints may be freed from dirt and loose fragments. A grouting of Portland cement should then be poured over the surface and rubbed into the joints, care being taken to wipe off with a dryish sponge all superfluous cement from the face of the pavement. Should any considerable inequalities remain, they may be rubbed down with a hard heavy stone and a little grit, till the whole is level and smooth. Then, when the floor is well washed and cleaned off, the operation, I doubt not, will prove to have been satisfactorily achieved.

"If the old backing is very good, I should endeavour to move the pavement in much larger pieces;-if it should be altogether rotten, and the tesseræ loose, I should $\operatorname{tr}_{j}$ strong glue and calico, instead of paste and brown paper, and endeavour to draw off all the tesseræ adhering to the calico. I should then re-back them, as described above, much in the same manner as frescoes are removed from walls."

Very recently several valuable mosaic pavements discovered in Yorkshire have been successfully taken up by a skilful and ingenious manipulator, Mr. Baines, sub-curator of the Museum of the Philosophical Society at York. One of these pavements, found in 1853, near Micklegate Bar, York, has been laid down in the lower apartment of the Hospitium, the building in which the Museum of Antiquities is placed. In this instance a stratum of plaster of Paris was formed over the face of the pavement, which was by that means raised in portions of moderate dimensions. It was then backed with Roman cement and slates, and carefully laid down on a bed of sand. The application of the liquid cement to the reverse, it should be observed, caused the layer of plaster to detach itself so perfectly that a cast might be taken from it, and a coloured facsimile produced, if desired, showing all the interstices and arrangement of the tessellæ. The other pavements, which are of fine character, have not at present been laid down. They were obtained from a Roman villa discovered near Easingwold. In this instance, Mr.: Baines states that he adopted a different process with great success. The face was first carefully cleansed from dust; the margins of the panels and chief divisions of the design were cut round, removing two rows of tesseræ between each, and dividing the whole work into slabs of manageable dimensions. Strong canvas was then attached to the surface by bookbinders' glue, the glwe being first applied to the tesseræ, and the cloth then laid upon it. In parts where the damp state of the floor prevented the canvas becoming firmly attached, a hot iron was passed over it with advantage. The sub-stratum was then cut away, and the portion of the floor taken up. Mr. Baines then removed all the lime at the back, leaving the tesseræ only adherent to the canvas. The mosaic work is then backed with slate, affixed by Roman cement. When firmly set, the various panels may then be laid in sand, the cloth removed by hot water, the interstices between the panels filled up by replacing the two rows of tesseræ which had been removed, as before described, and any other defective portions made good. Mr. Baines proposes to make use of Roman cement for every purpose connected with relaying the pavement. By this mode of proceeding the face of the work may be rendered perfectly level, an advantage not to be attained where the plaster of Paris is used. 